\title{
Guanosine 5'-diphosphate 3'-diphosphate (ppGpp), guanosine 5'-diphosphate 3'- monophosphate (ppGp) and antibiotic production in Streptomyces clavuligerus
}

\author{
Christine Jones, $\uparrow$ Arthur Thompson and Reg England \\ Author for correspondence: Reg England. Tel: +44 1772 893513. Fax: +44 1772892929. \\ e-mail: r.england@uclan.ac.uk
}

Department of Applied Biology, University of Central Lancashire, Preston PR1 2HE, UK

Keywords: Streptomyces clavuligerus, stringent response, ppGpp, ppGp, antibiotics

\section{INTRODUCTION}

Streptomycetes produce a wide range of secondary metabolites, including antibiotics. A characteristic in the production of antibiotics is that they are produced when micro-organisms are growing at low specific growth rates. This implies that during batch culture, genes coding for the enzymes (synthases) necessary for antibiotic biosynthesis are repressed at high growth rates. The factor(s) that control the derepression of antibiotic synthases is probably the deficiency of one, or more, growth-limiting nutrients. At the moment very little is known about the nature and mode of action of the intracellular effector(s) that regulate antibiotic biosynthesis in streptomycetes. One potential effector molecule is guanosine $5^{\prime}$-diphosphate $3^{\prime}$-diphosphate (ppGpp).

When cells of bacteria, such as Escherichia coli, experience nutrient limitation, their growth rate decreases and they make a series of rapid adjustments to their metabolism. One response elicited is the stringent response, characterized by a reduction in the rate of stable RNA (i.e. rRNA, tRNA) accumulation and mRNA for ribosomal

† Present address: Department of Biological Sciences, Manchester Metropolitan University, Chester Street, Manchester M1 5GD, UK.

Abbreviations: DCW, dry cell weight; IPNS, isopenicillin N synthase. proteins and triggered by the binding of uncharged tRNA to ribosomes (Cashel, 1975). The stringent response is mediated by an accumulation of ppGpp, which is the product of the $\operatorname{rel} A$ gene (Cashel \& Rudd, 1987). In $E$. coli, growth rate is an inverse linear function of the intracellular ppGpp concentration, which suggests that ppGpp has a significant role in growth rate control (Sarubbi et al., 1988).

Several authors have shown that the stringent response and $\mathrm{ppGpp}$ production occur in a wide range of Streptomyces species (Riesenberg et al., 1984; Ochi, 1986; Strauch et al., 1991; Bascaran et al., 1991). Simuth et al. (1979) described a correlation between the onset of antibiotic production and ppGpp levels in S. aureofaciens. However, An \& Vining (1978) had previously concluded that streptomycin production by $S$. griseus was not mediated by ppGpp. More recently, Ochi (1990a, b) has described the isolation of $r e l C$ mutants that produced very low levels of ppGpp and were deficient in antibiotic production. However, Bascaran et al. (1991) isolated relC mutants of $S$. clavuligerus and could not find a correlation between antibiotic production and the stringent response. Moreover, Strauch et al. (1991) have concluded that increased levels of ppGpp alone are not sufficient to initiate antibiotic biosynthesis in $S$. coelicolor. Thus, there are conflicting interpretations concerning the role of ppGpp in the regulation of antibiotic biosynthesis in streptomycetes. 
In order to study the role of ppGpp more fully we have initiated a physiological and molecular biology programme using the industrially relevant organism $S$. clavuligerus. In this paper we describe levels of ppGpp, ppGp (guanosine 5'-diphosphate 3'-monophosphate) and $\beta$-lactam antibiotics, during batch fermentation of $S$. clavuligerus.

\section{METHODS}

Organisms and growth conditions. S. clavuligerus NRRL 3585 was grown at $28^{\circ} \mathrm{C}$ as a batch culture in a 16 litre Bioengineering L1523 fermenter with a working volume of 12 litres, or in 1 litre triple-baffled flasks containing $200 \mathrm{ml}$ medium. The $\mathrm{pH}$ was maintained at 6.9 with $50 \mathrm{mM}$ MOPS. In all cultures the chemically defined medium (FM) was as described by Aharonowitz \& Demain (1979), except that under carbon-limiting conditions $4 \mathrm{~g}$ glycerol $\mathrm{l}^{-1}$ was used; under nitrogen-limiting conditions asparagine $\left(2 \mathrm{~g} \mathrm{l}^{-1}\right)$ was replaced by $0.54 \mathrm{~g} \mathrm{NH}_{4} \mathrm{Cl} \mathrm{l}^{-1}$ and under phosphate-limiting conditions $0.35 \mathrm{~g} \mathrm{~K}_{2} \mathrm{HPO}_{4} \mathrm{l}^{-1}$ $(1.5 \mathrm{mM})$ was used. A linear response of biomass concentration to an increase in the individual limiting substrate concentration was taken as proof that all nutrients, other than the required limiting nutrient, were in excess. Spores of $S$. clavuligerus were used to inoculate seed medium (Aharonowitz \& Demain, 1979) and incubated in triple-baffled Erlenmeyer flasks for $48 \mathrm{~h}$ in a rotary shaking incubator at $200 \mathrm{r.p} . \mathrm{m}$. and $28^{\circ} \mathrm{C}$. The resulting seed cultures were washed with medium of the same composition as used for each of the fermentations before being used as inoculum at $2.5 \%(\mathrm{v} / \mathrm{v})$. Growth was estimated by measuring the dry cell weight (DCW).

Assay of nucleotide pools. Samples of culture $(100 \mathrm{ml})$ were removed from the fermenters and filtered through $90 \mathrm{~mm}$ diameter filter papers (Millipore, $0.45 \mu \mathrm{m}$ pore size), extracted with cold $1 \mathrm{M}$ formic acid for $1 \mathrm{~h}$, centrifuged for $10 \mathrm{~min}$ at $6000 \mathrm{~g}$, and the supernatants filtered through nitrocellulose (Gelman, $0.45 \mu \mathrm{m}$ pore size). The filtrates were freeze-dried and resuspended in $500 \mu$ l deionized distilled water. The intracellular concentrations of nucleotides were assayed by HPLC on a Partisil 10 SAX column (Whatman) with a gradient of $7 \mathrm{mM}$ $\mathrm{K}_{2} \mathrm{HPO}_{4}$, pH 4.0, to $0.5 \mathrm{M} \mathrm{KH}_{2} \mathrm{PO}_{4} / 0.5 \mathrm{M} \mathrm{Na}_{2} \mathrm{SO}_{4}$, pH 5.4, at a flow rate of $1.5 \mathrm{ml} \mathrm{min}^{-1}$. Nucleotides were detected at $254 \mathrm{~nm}$. The concentrations of nucleotides were expressed relative to mycelial dry weight.

Antibiotic determinations. Samples of filtered fermentation broth were assayed for $\beta$-lactam antibiotics by HPLC on a Nucleosil C18 ODS $25 \mathrm{~cm}$ column (Jones Chromatography). The column was pre-conditioned with $60 \mathrm{ml} \mathrm{4.5} \mathrm{mM} \mathrm{tetrabutyl}$ ammonium bromide (TBAB) in $0.05 \mathrm{M} \mathrm{K}_{2} \mathrm{HPO}_{4}$ $\left(\mathrm{pH} \mathrm{3.0)} /\right.$ methanol $(85: 15, \mathrm{v} / \mathrm{v})$ at $1.5 \mathrm{ml} \mathrm{min}^{-1}$ and then equilibrated with $0.15 \mathrm{mM}$ TBAB in $0.05 \mathrm{M} \mathrm{K}_{2} \mathrm{HPO}_{4}$ $(\mathrm{pH} 3.0) /$ methanol $(95: 5, \mathrm{v} / \mathrm{v})$. Samples $(20 \mu \mathrm{l})$ of culture filtrates were analysed at a flow rate of $1.5 \mathrm{ml} \mathrm{min}^{-1}$ and antibiotics were detected at $220 \mathrm{~nm}$.

Nutrient consumption. Glycerol in the fermentation broth was determined by the method of Bok \& Demain (1977). Asparagine was determined according to Plummer (1971). Ammonium was measured by the method of Weatherburn (1967) and phosphate was determined by the method of Golterman et al. (1978).

Western blotting. Isopenicillin $\mathrm{N}$ synthase (IPNS) expression was determined by Western blot analysis. Cells $(10 \mathrm{ml})$ from the fermenter were washed and resuspended in $10 \mathrm{ml} 0.05 \mathrm{M}$ Tris $/ \mathrm{HCl}$ buffer, $\mathrm{pH} 7.2$, containing $0.1 \mathrm{mM}$ dithiothreitol, $0.01 \mathrm{mM}$ disodium EDTA and $1 \mathrm{mM}$ phenylmethylsulfonyl fluoride. Cells were broken by passage through a pre-cooled French press at $70-80 \mathrm{MPa}$. Cell debris and unbroken cells were removed by centrifugation at $10000 \mathrm{~g}$ for $20 \mathrm{~min}$ at $4{ }^{\circ} \mathrm{C}$. Protein content of the cell-free extract was determined according to the method of Bradford (1976). Proteins and prestained lowrange molecular mass markers (Bio-Rad) were separated by SDS-PAGE $(12 \%, w / v$, acrylamide), using the method of Laemmli (1970). After SDS-PAGE, proteins were transferred to nitrocellulose filters at $30 \mathrm{~V}$ overnight in a Trans-Blot apparatus (Bio-Rad) according to the manufacturer's instructions. Transferred proteins were probed with IPNS polyclonal antibody as whole serum (1:500 dilution); the membranes were washed with $0.01 \mathrm{M}$ Tris $/ \mathrm{HCl}, \mathrm{pH} 8.0$, and $0.15 \mathrm{M} \mathrm{NaCl}$ and incubated for $1 \mathrm{~h}$ with a $1: 3000$ dilution of goat anti-rabbit IgG alkaline phosphatase conjugate (Sigma), and washed again. The membranes were then developed with Western blue reagent (Promega). Polyclonal antibodies were prepared in rabbits to a peptide sequence derived from the $S$. clavuligerus IPNS protein. The peptide was conjugated to bovine serum albumin and this conjugate was used for immunization of New Zealand White rabbits. Cell-free extracts of E. coli DS941, containing the IPNS gene on PMZR100, were run on each polyacrylamide gel to verify IPNS expression. Antisera and E. coli DS941 were kind gifts of Dr B. Barton, SmithKline Beecham Pharmaceuticals, Worthing, UK.

Reproducibility. Figs 1-6 show representative results from single experiments, all of which were repeated twice, and all parameter determinations were simultaneously carried out at least twice. Fermenter-grown cultures were sampled every hour, but for clarity not all sample points are shown in the figures. Fig. 7 shows representative results from single experiments carried out at least twice.

Chemicals. ppGp, ppGpp and pppGpp were gifts from Mercian Corporation, Japan. Cephamycin C was a gift of Merck and Co., NJ, USA. Clavulanic acid and IPNS antiserum were kind gifts of SmithKline Beecham Pharmaceuticals, UK. All other chemicals were of Analar or HPLC grade wherever possible.

\section{RESULTS}

\section{Production of cephamycin C and clavulanic acid in batch culture}

Fermentation medium (FM). Cephamycin $C$ was initially detected after $30 \mathrm{~h}$ of fermentation, and production continued until early stationary phase. Onset of the stationary phase corresponded to the depletion of asparagine (Fig. 1a). Clavulanic acid was not detected, due to the repressive levels of phosphate $(20 \mathrm{mM})$ maintained during the course of the fermentation. The biosynthesis of clavulanic acid is repressed at phosphate concentrations above $10 \mathrm{mM}$ (Romero et al., 1984). Fig. 1(b) shows that the pool of ppGpp remained constant below the level of detection [ $<3 \mathrm{pmol}(\mathrm{mg} \mathrm{DCW})^{-1}$ ] until $28 \mathrm{~h}$, when a rapid burst was observed, reaching $23 \mathrm{pmol}$ (mg DCW $)^{-1}$. The pool returned to basal levels within $60 \mathrm{~min}$ and remained at this level for the rest of the fermentation. At $20 \mathrm{~h}$, corresponding to the onset of the exponential growth phase, another nucleotide was detected which had an HPLC retention time identical to that of pure ppGp. Pure ppGp and the new nucleotide were shown by HPLC analysis to be completely hydrolysed after incubation with bacterial alkaline phosphatase yet resistant to hydrolysis after incubation in $0.3 \mathrm{M} \mathrm{KOH}$. Further characterization 

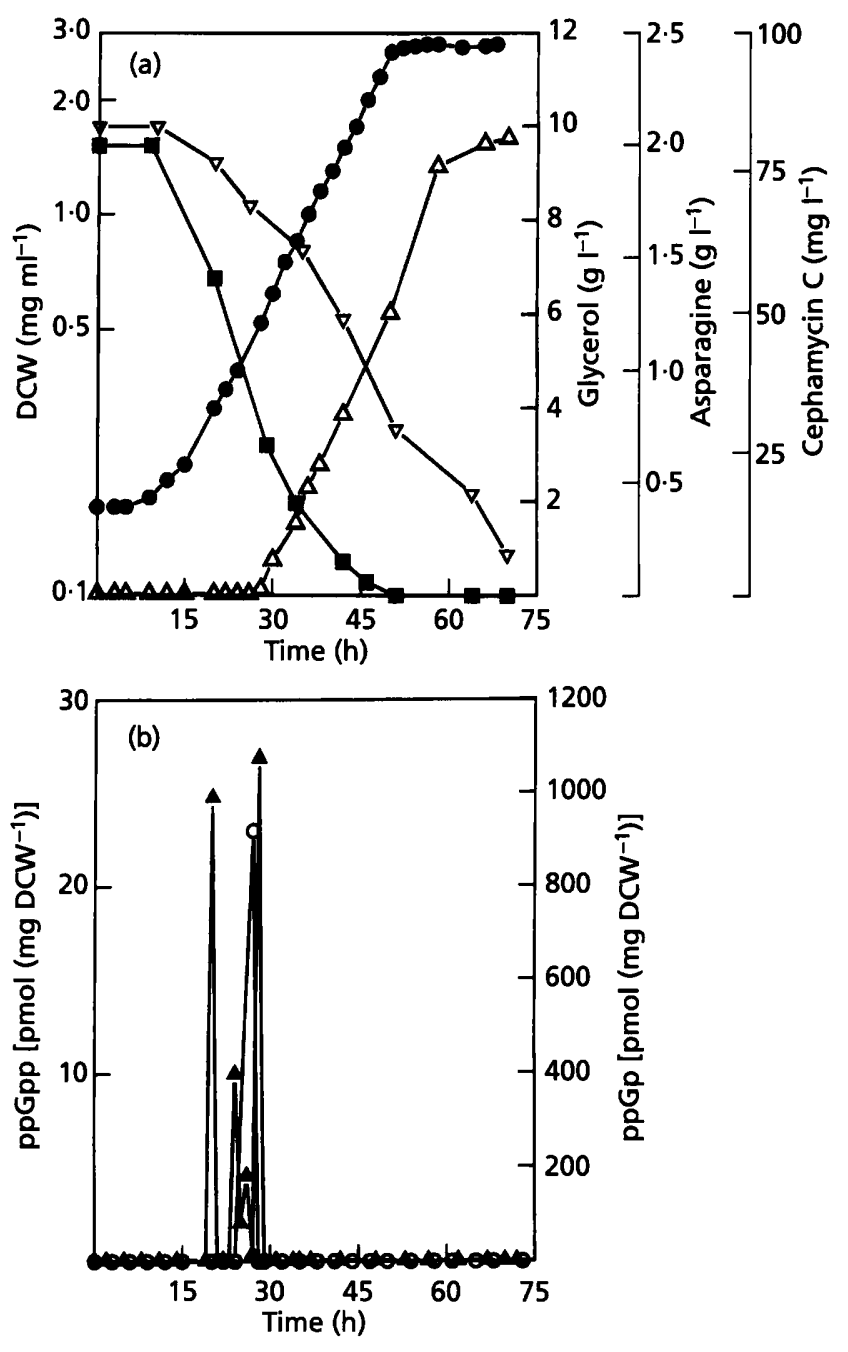

Fig. 1. Fermentation profile during batch-culture growth in FM. 5 . clavuligerus was grown as 12 litre cultures in a Bioengineering fermenter at $28^{\circ} \mathrm{C}$ and 500 r.p.m. Dissolved $\mathrm{O}_{2}$ tension above $50 \%$ air saturation was maintained during the course of the fermentation. (a) Growth as dry cell weight (O), cephamycin $C(\triangle)$, asparagine $(\square)$ and glycerol $(\nabla)$. (b) Intracellular concentration of ppGpp (O) and ppGp ( $\mathbf{A})$.

by HPLC showed that pure ppGp was hydrolysed during incubation with 2 units $\mathrm{ml}^{-1}$ of snake venom phosphodiesterase (Sigma) for $24 \mathrm{~h}$ at $37^{\circ} \mathrm{C}$ in $50 \mathrm{mM}$ Tris/ $\mathrm{HCl}$ buffer ( $\mathrm{pH} 9 \cdot 0)+1 \mathrm{mM} \mathrm{MgCl}_{2}$ but was unaffected in the absence of enzyme. The same result was obtained with a fermentation sample treated in a similar manner. The product formed after snake venom phosphodiesterase treatment of pure ppGp and the fermentation sample was shown by HPLC to be further hydrolysed after incubation with 5 units $\mathrm{ml}^{-1}$ of ryegrass $3^{\prime}$-nucleotidase (Sigma) for $24 \mathrm{~h}$ at $37^{\circ} \mathrm{C}$. This result confirmed that the main snake venom phosphodiesterase hydrolysis product of both ppGp and the fermentation sample was $p G 3$ 'p. These results are consistent with published data for $\mathrm{ppGp}$ ( $\mathrm{PaO}$ \& Gallant, 1979) and indicate that the new HPLC peak observed in fermentation samples can be assigned to

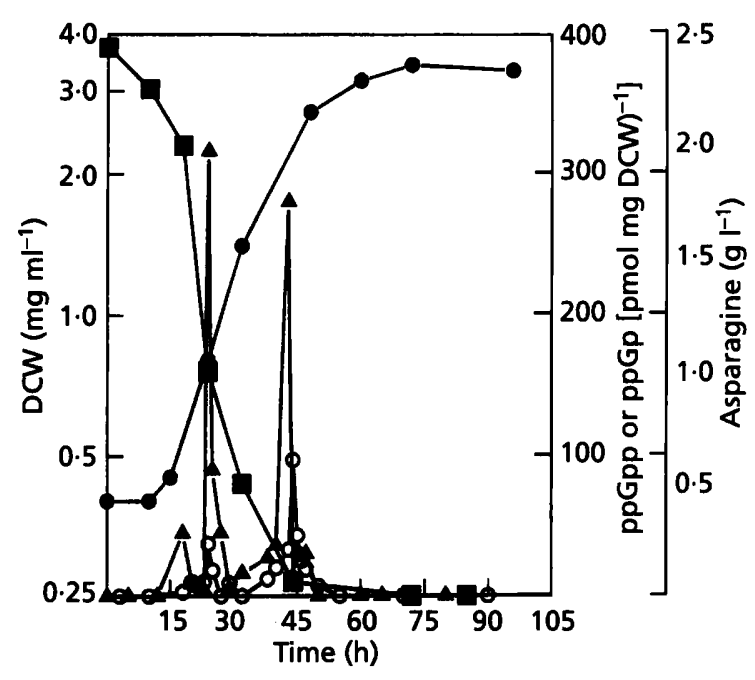

Fig. 2. Fermentation profile during shake-flask batch culture in FM. S. clavuligerus was grown as $200 \mathrm{ml}$ cultures in triplebaffled 1 litre Erlenmeyer flasks in a rotary shaking incubator at $28^{\circ} \mathrm{C}$ and 200 r.p.m. Growth as dry cell weight (O), asparagine (目), ppGpp (O) and ppGp ( $\Delta$ ).

ppGp. During the fermentation of $S$. clavuligerus, ppGp was detected between 20 and $29 \mathrm{~h}$ at levels up to $1100 \mathrm{pmol}(\mathrm{mg} \mathrm{DCW})^{-1}$. Production of ppGpp and ppGp occurred prior to the detection of cephamycin $C$ in the fermentation broth and corresponded to a rapid downturn in the levels of asparagine and glycerol in the medium. We were unable to detect pppGpp during the course of any fermentation.

When $S$. clavuligerus was grown as a shake-flask culture, appearance of $\mathrm{ppGp}$ production at $16 \mathrm{~h}[45 \mathrm{pmol}(\mathrm{mg}$ DCW $)^{-1}$ ] corresponded to the start of exponential growth and a rapid downturn in asparagine levels (Fig. 2). Peaks of ppGp were also observed at $24 \mathrm{~h}$ [316 pmol (mg $\left.\mathrm{DCW})^{-1}\right]$ and at $43 \mathrm{~h}\left[280 \mathrm{pmol}(\mathrm{mg} \mathrm{DCW})^{-1}\right]$, the latter corresponding to late exponential growth and depletion of asparagine. Production of ppGpp was similar to that reported by An \& Vining (1978) for S. griseus. Peaks were observed at $24 \mathrm{~h}\left[37 \mathrm{pmol}(\mathrm{mg} \mathrm{DCW})^{-1}\right]$, and also after $44 \mathrm{~h}$, [97 pmol (mg DCW $)^{-1}$ ], corresponding to the late exponential growth phase.

Nitrogen limitation. Cephamycin $C$ was initially detected after $34 \mathrm{~h}$ and production followed a growth-associated pattern (Fig. 3a). Exhaustion of ammonium at $48 \mathrm{~h}$ corresponded to the onset of the stationary phase, and was followed by the cessation of cephamycin $\mathrm{C}$ production after $50 \mathrm{~h}$. Clavulanic acid was not detected during the fermentation. Fig. 3(b) demonstrates that the pool of ppGpp remained at a basal level until $32 \mathrm{~h}$ when a rapid burst was detected, reaching $17 \mathrm{pmol}(\mathrm{mg} \mathrm{DCW})^{-1}$. The ppGpp level decayed rapidly over the following $60 \mathrm{~min}$, returning to basal levels, and remained at that level for the rest of the fermentation. Production of ppGp was noted between 22 and $28 \mathrm{~h}$, at levels up to $1.75 \mathrm{nmol}(\mathrm{mg}$ $\mathrm{DCW})^{-1}$. The initial burst of ppGp corresponded to the 

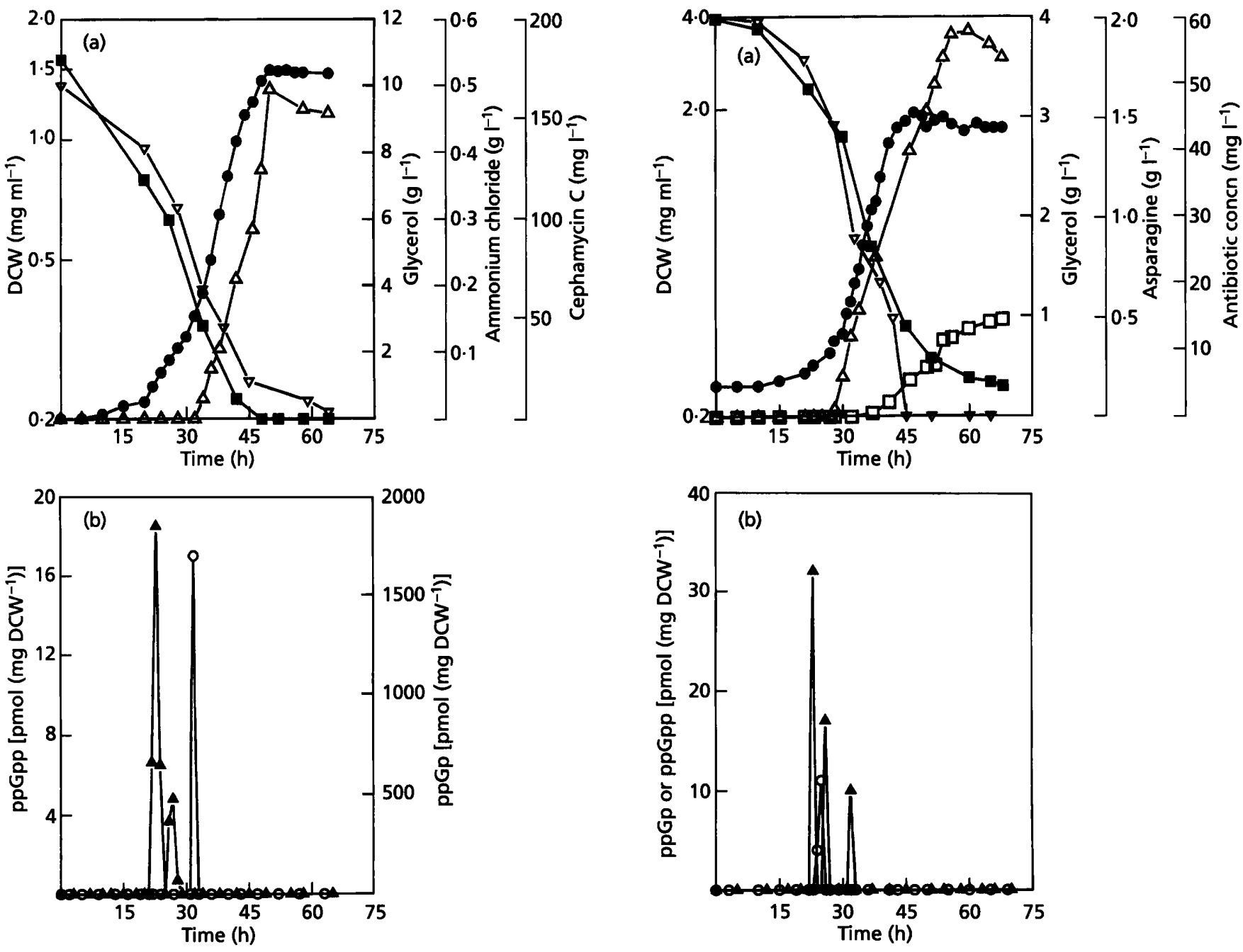

Fig. 3. Fermentation profile during batch-culture growth under nitrogen limitation. Fermenter conditions were as described in Fig. 1. (a) Growth as dry cell weight $(O)$, cephamycin $C(\Delta)$, ammonium $(\square)$ and glycerol $(\nabla)$. (b) Intracellular concentration of ppGpp (O) and ppGp ( $\mathbf{\Delta}$.

onset of the exponential growth phase. The production of ppGpp and ppGp occurred prior to the detection of cephamycin $C$ in the fermentation broth. pppGpp was not detected during the fermentation.

Carbon limitation. Cephamycin $\mathrm{C}$ was detected after $28 \mathrm{~h}$ and production followed a growth-associated profile (Fig. 4a), ceasing after $58 \mathrm{~h}$ of fermentation. Depletion of glycerol caused the onset of the stationary phase at $48 \mathrm{~h}$. Clavulanic acid was initially detected after $36 \mathrm{~h}$ and followed a growth-dissociated profile, with levels remaining low during the course of the fermentation. Fig. 4(b) shows that the pool of ppGpp remained at a basal level until a burst was detected at $25 \mathrm{~h}$, reaching $10.5 \mathrm{pmol}$ $(\mathrm{mg} \mathrm{DCW})^{-1}$, and decaying back to basal level within $60 \mathrm{~min}$. ppGp was initially detected at $22 \mathrm{~h}[32 \mathrm{pmol}$ (mg $\mathrm{DCW})^{-1}$ ], corresponding to the onset of the exponential growth phase and $6 \mathrm{~h}$ prior to the appearance of

Fig. 4. Fermentation profile during batch-culture growth under carbon limitation. Fermenter conditions were as described in Fig. 1. (a) Growth as dry cell weight (O), cephamycin $C(\triangle)$, clavulanic acid $(\square)$, asparagine $(\square)$ and glycerol $(\nabla)$. (b) Intracellular concentration of ppGpp $(O)$ and ppGp $(\boldsymbol{\Delta})$.

cephamycin $\mathrm{C}$ in the medium. Production of ppGp was also detected between 30 and $32 \mathrm{~h}$ [10 pmol (mg $\mathrm{DCW})^{-1}$ ], $4 \mathrm{~h}$ before clavulanic acid was detected in the fermentation broth. pppGpp was not detected during the fermentation.

Phosphate limitation. Cephamycin $C$ and clavulanic acid were produced in a growth-dissociated manner, and were initially detected after $46 \mathrm{~h}$, corresponding to the late exponential growth phase (Fig. 5a). Phosphate depletion from the medium after $52 \mathrm{~h}$ corresponded to the onset of the stationary phase. Phosphate limitation severely decreased the biomass levels; the decrease was considerably greater than reported by Lebrihi et al. (1987). However, the kinetics of cephamycin $\mathrm{C}$ and clavulanic acid production were very similar to the kinetics described by these authors. Fig. 5(b) shows that a burst of ppGpp was initially seen at $24 \mathrm{~h}\left[325 \mathrm{pmol}\left(\mathrm{mg} \mathrm{DCW}^{-1}\right]\right.$, at the onset 

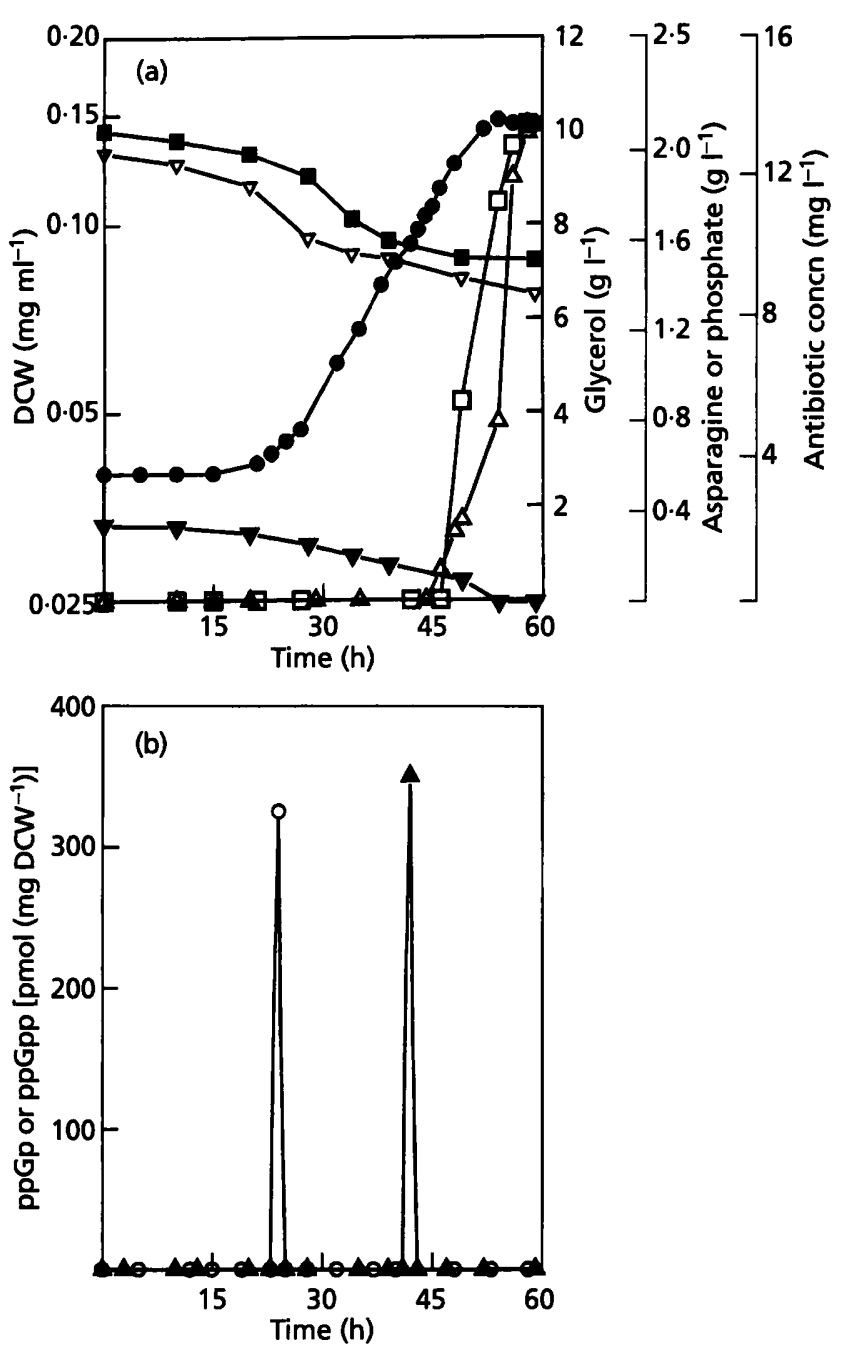

Fig. 5. Fermentation profile during batch-culture growth under phosphate limitation. Fermenter conditions were as described in Fig. 1. (a) Growth as dry cell weight $(0)$, cephamycin $C(\triangle)$, clavulanic acid $(\square)$, asparagine $(\square)$, glycerol $(\nabla)$ and phosphate (V). (b) Intracellular concentration of ppGpp (O) and ppGp (A).

of exponential growth. At $42 \mathrm{~h}$, a burst of ppGp was noted $\left[350\right.$ pmol $\left.(\mathrm{mg} \mathrm{DCW})^{-1}\right], 4 \mathrm{~h}$ before cephamycin $\mathrm{C}$ and clavulanic acid were detected in the medium. pppGpp was not detected during the fermentation.

\section{Stringent response in S. clavuligerus}

In order to determine whether ppGp was produced by $S$. clavuligerus during the stringent response, cells growing exponentially in FM+1\% Casamino acids were transferred to the same medium without Casamino acids. Fig. 6 shows that maximal ppGp levels were detected $10 \mathrm{~min}$ after shiftdown [118 pmol (mg DCW $)^{-1}$ ] and preceded the typical transient accumulation of ppGpp observed $15 \mathrm{~min}$ after shiftdown $\left[35 \mathrm{pmol}(\mathrm{mg} \mathrm{DCW})^{-1}\right]$. These kinetics are not consistent with a precursor-product relationship as would be expected if ppGp were merely a

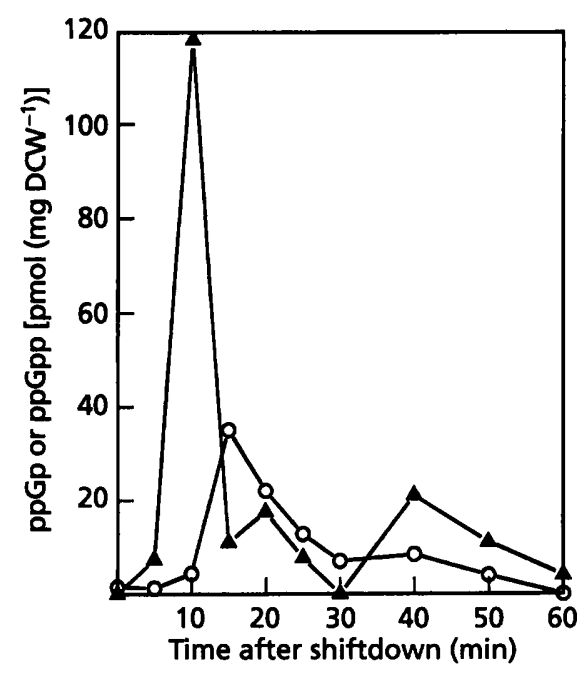

Fig. 6. Changes in the intracellular concentration of ppGpp (O) and ppGp $(\Delta)$ after nutrient shiftdown of an exponentially growing culture of $S$. clavuligerus. Cells were grown to midexponential phase in $\mathrm{FM}+1 \%(\mathrm{w} / \mathrm{V})$ Casamino acids. Cells were harvested by filtration and transferred to fresh FM without Casamino acids and then incubated at $28^{\circ} \mathrm{C}$ with shaking. At the indicated times cells were filtered and extracted and the nucleotides were separated and quantified by HPLC (see Methods).

degradation product of ppGpp. We have been unable to detect $\mathrm{ppGpp}$ or $\mathrm{ppGp}$ during nutrient shiftdown to carbon or phosphate limitation.

In order to assess further the possibility that $\mathrm{ppGp}$ was a degradation product of $\mathrm{ppGpp}$, authentic pure standard was incubated at $25^{\circ} \mathrm{C}$ and $37^{\circ} \mathrm{C}$ for up to $2 \mathrm{~h}$ in Tris/acetate/salts buffer ( $\mathrm{pH} \mathrm{8.0)}$, with or without cellfree extracts derived from early and late exponential cells of $S$. clavuligerus. Nucleotide extraction and resolution by HPLC were performed as described in Methods. We were unable to detect any significant hydrolysis of ppGpp.

\section{Western blot analysis of IPNS}

S. clavuligerus grown in FM produced IPNS at $21 \mathrm{~h}$ (Fig. 7a), in nitrogen-limiting (Fig. 7b) and carbon-limiting (Fig. 7c) media at $23 \mathrm{~h}$ and in phosphate-limiting (Fig. 7d) conditions at $43 \mathrm{~h}$. Under all nutrient conditions the appearance of the enzyme was immediately preceded by production of $\mathrm{ppGp}$ in the cells. There was no correlation with the timing of ppGpp production. It is interesting to note that under nitrogen and phosphate limitation there was an apparent increase in amount of IPNS, as determined by band intensities, compared with growth in FM or under carbon limitation.

\section{DISCUSSION}

In contrast to the prolonged lag phase exhibited by $S$. clavuligerus after inoculation into specific nutrient-limited media (Figs 3-5), a reduced lag period was seen following 
(a)

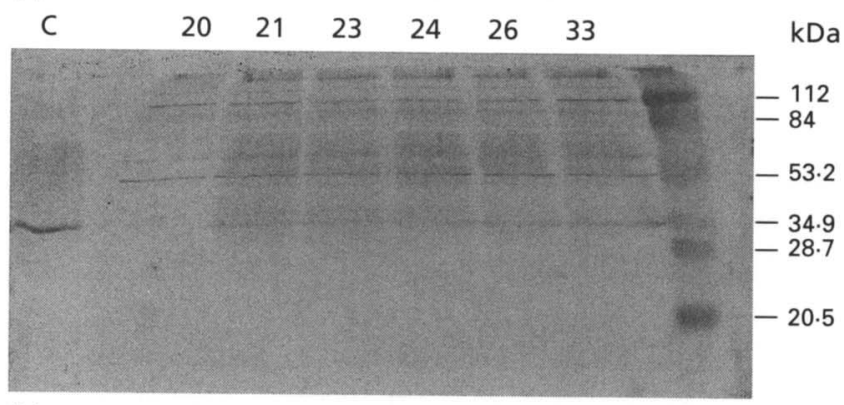

(b)

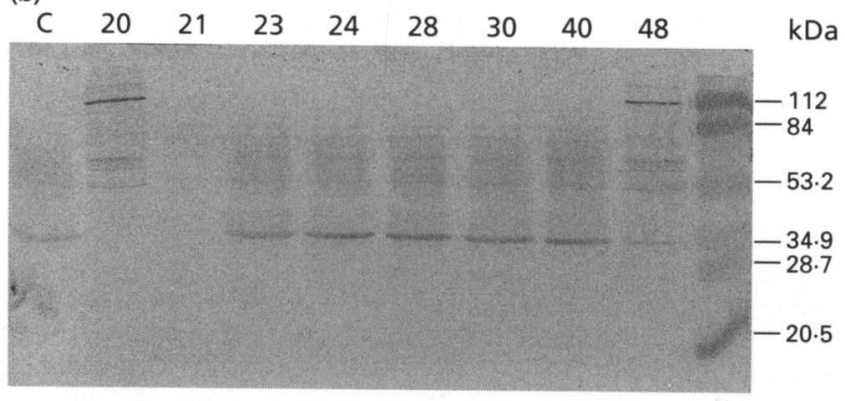

(c)

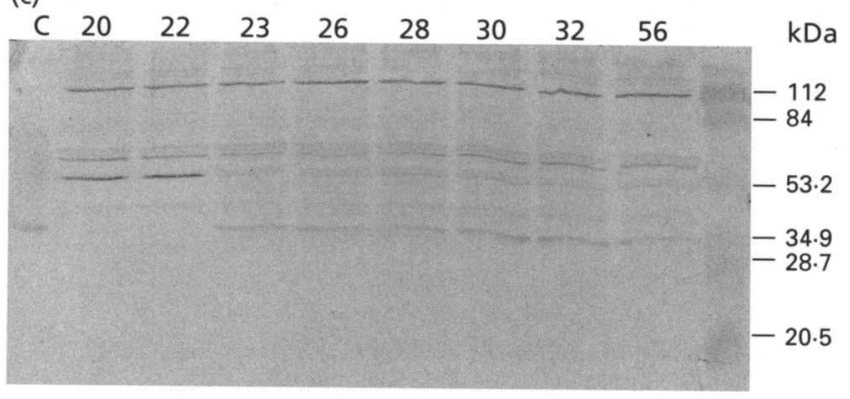

(d)

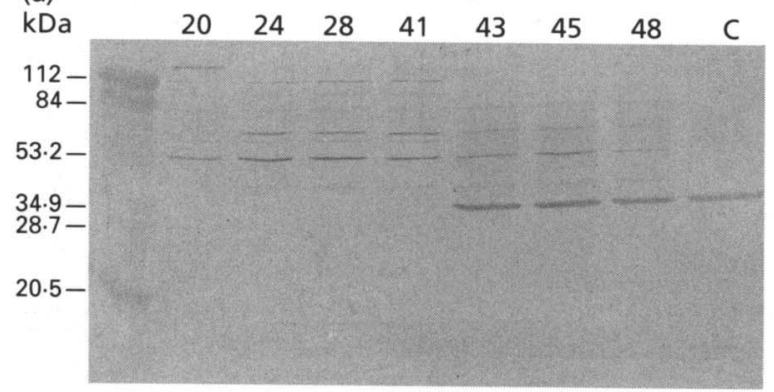

Fig. 7. Western immunoblot analysis of proteins in cell-free extracts of S. clavuligerus: (a) FM, (b) nitrogen limitation, (c) carbon limitation and (d) phosphate limitation. Samples were transferred to nitrocellulose membranes, which were incubated with a 1:500 dilution of IPNS antiserum followed by a 1:3000 dilution of goat anti-rabbit IgG alkaline phosphatase conjugate; $50 \mu \mathrm{g}$ protein was loaded in all experiments. Times indicated are hours of fermentation. The control (lane C) in each experiment was cell-free extract derived from $E$. coli DS941 expressing PMZR100, which contains the IPNS gene. Molecular mass standards are prestained low range (Bio-Rad). The molecular mass of IPNS is $35 \mathrm{kDa}$.

inoculation into the nutritionally more favourable FM (Fig. 1a, Fig. 2). This difference is attributed to a period of adjustment required by the organism following transfer from the nutritionally rich seed medium to the growthlimiting defined medium.

During batch culture of $S$. clavuligerus, grown under various nutrient conditions in a 16 litre laboratory-scale fermenter, ppGpp was produced either at the beginning of, or during, exponential growth, and prior to the appearance of cephamycin $C$ and clavulanic acid in the fermentation broth. We did not observe ppGpp at the end of exponential growth in any fermenter-grown culture. These results differ from those of Bascaran et al. (1991) for $S$. clavuligerus; however, these workers used a different growth medium from that used in this study, and they did not sample the cultures until $28 \mathrm{~h}$ post-inoculation and may have missed a burst of ppGpp. In all fermentations we consistently detected, by HPLC, the production of a new nucleotide before the appearance of antibiotics in the medium. The new nucleotide was hydrolysed by snake venom phosphodiesterase to pG3'p, which was then further hydrolysed by ryegrass $3^{\prime}$-nucleotidase. This enzyme hydrolysis pattern was identical to that of pure $p p G p$ and hence we attributed the nucleotide to ppGp. It is interesting to note that in contrast to ppGpp, where single peaks are observed, multiple peaks of $p p G p$ are produced; the reason(s) for this is presently unclear.

The production of $\mathrm{ppGp}$ was found not to be due to the degradation of ppGpp. It is known that the $3^{\prime}-\beta$ phosphate residue of $\mathrm{ppGpp}$ is sensitive to acid hydrolysis and could provide a non-enzymic route for $\mathrm{ppGp}$ production. Figs 3(a) and 5(b) specifically show that ppGpp is not hydrolysed during the acid extraction conditions employed in this study. This was confirmed when we were unable to detect any significant hydrolysis of pure ppGpp following incubation with cell-free extracts of $S$. clavuligerus.

It has been reported that ppGp is produced following induction of the stringent response in $E$. coli (Pao \& Gallant, 1979) and Bacillus subtilis (Nishino et al., 1979). A similar observation was reported by Strauch et al. (1991) for $S$. coelicolor following a nutrient shiftdown. We have also observed ppGp production in S. clavuligerus following nutrient shiftdown from an amino-acid-containing medium to a minimal medium. Following shiftdown of $S$. clavuligerus to a carbon- or phosphate-limiting minimal medium we were unable to detect production of $\mathrm{ppG}$ or ppGpp. This suggests that production of $p p G p$ and ppGpp in $S$. clavuligerus is in response to an alteration in levels of nitrogen available to the cells.

Immunoblots with polyclonal antibodies to IPNS (Fig. $7 \mathrm{a}-\mathrm{d})$ showed that the enzyme is produced following a reduction of the nitrogen or carbon concentration in the growth medium and immediately after production of ppGp. It remains to be elucidated whether there is a positive relationship between production of $\mathrm{ppGp}$ and the appearance of IPNS. Earlier work has shown that the biosynthesis of cephamycin C (Brana et al., 1986) and clavulanic acid (Romero et al., 1984) are strongly regulated by nitrogen sources. On the basis of data from the fermentation experiments and nutrient shiftdowns, it is intriguing to speculate that the production of $\mathrm{ppGp}$ may 
be involved in nitrogen regulation of antibiotic biosynthesis in streptomycetes.

Many questions are now raised concerning the role of ppGp: how it is produced and its relationship with ppGpp and the protein biosynthetic machinery in $S$. clavuligerus. Preliminary experiments have demonstrated that $70 \mathrm{~S}$ ribosomes prepared from S. clavuligerus are able to produce $\mathrm{ppGpp}$ and $\mathrm{ppGp}$; however following a highsalt wash, ppGpp production is significantly diminished. After further salt washing the ribosomes still retain the activity to produce levels of ppGp similar to those observed from control ribosomes (results not shown); it is therefore tempting to suggest that ppGp synthesis is not overtly associated with any ppGpp synthetic activity. These results suggest that the ppGp levels observed in our fermentation experiments are physiologically representative and that production is associated with the ribosomes, possibly triggered by nitrogen depletion.

\section{ACKNOWLEDGEMENTS}

We are grateful to BBSRC for financial support (grant no. GR/H51729). We especially thank John Hodgson and Liz Lawlor (SKB) and also Merv Bibb (John Innes Institute) for many helpful discussions.

\section{REFERENCES}

Aharonowitz, Y. \& Demain, A. L. (1979). Nitrogen nutrition and regulation of cephalosporin production in Streptomyces clavuligerus. Can J Microbiol 25, 61-67.

An, G. \& Vining, L. C. (1978). Intracellular levels of guanosine $5^{\prime}$ diphosphate $3^{\prime}$-diphosphate (ppGpp) and guanosine $5^{\prime}$ triphosphate $3^{\prime}$-diphosphate (pppGpp) in cultures of Streptomyces griseus producing streptomycin. Can J Microbiol 24, 502-511.

Bascaran, V., Sanchez, L., Hardisson, C. \& Brana, A. F. (1991). Stringent response and initiation of secondary metabolism in Streptomyces clavuligerus. J Gen Microbiol 137, 1625-1634.

Bok, S. H. \& Demain, A. L. (1977) An improved colorimetric assay for polyols. Anal Biochem 81, 18-20.

Bradford, M. M. (1976). A rapid and sensitive method for the quantitation of microgram quantities of protein utilizing the principle of protein-dye binding. Anal Biochem 72, 248-254.

Brana, A. F., Wolfe, S. \& Demain, A. L. (1986). Relationship between nitrogen assimilation and cephalosporin synthesis in Streptomyces clavuligerus. Arch Microbiol 146, 46-51.

Cashel, M. (1975). Regulation of bacterial ppGpp and pppGpp. Annu Rev Microbiol 29, 301-318.

Cashel, M. \& Rudd, K. E. (1987). The stringent response. In Escherichia coli and Salmonella typhimurium: Cellular and Molecular
Biology, pp. 1410-1438. Edited by F. C. Neidhardt and others. Washington, DC: American Society for Microbiology.

Golterman, H. L., Clymo, R. S. \& Ohnstad, M. A. M. (1978). Methods for Physical and Chemical Analysis of Fresh Waters, pp. 112-113. Oxford: Blackwell Scientific Publications.

Laemmli, U. K. (1970). Cleavage of structural proteins during assembly of the head of bacteriophage T4. Nature 227, 680-685.

Lebrihi, A., Germain, P. \& Lefebvre, G. (1987) Phosphate repression of cephamycin and clavulanic acid production by Streptomyces clavuligerus. Appl Microbiol Biotechnol 26, 130-135.

Nishino, T., Gallant, J., Shalit, P., Palmer, L. \& Wehr, T. (1979) Regulatory nucleotides involved in the rel function of Bacillus subtilis. J Bacteriol 140, 671-679.

Ochi, K. (1986). Occurrence of the stringent response in Streptomyces sp. and its significance for the induction of morphological and physiological differentiation. J Gen Microbiol 132, 2621-2631.

Ochi, K. (1990a). Streptomyces relC mutants with an altered ribosomal protein ST-L11 and genetic analysis of a Streptomyces griseus relC mutant. J Bacteriol 172, 4008-4016.

Ochi, K. (1990b). A relaxed ( $\mathrm{rel}$ ) mutant of Streptomyces coelicolor A3(2) with a missing ribosomal protein lacks the ability to accumulate ppGpp, A factor and prodigiosin. J Gen Microbiol 136, 2405-2415.

Pao, C. C. \& Gallant, J. (1979). A new nucleotide involved in the stringent response in Escherichia coli. J Biol Chem 254, 688-692.

Plummer, D. T. (1971). Quantitative examination of proteins and amino acids. In An Introduction to Practical Biochemistry, pp. 153-160. London: McGraw Hill.

Riesenberg, D., Bergter, F. \& Kari, C. (1984). Effect of serine hydroxymate and methyl $\alpha$-D-glucopyranoside treatment on nucleoside polyphosphate pools, RNA and protein accumulation on Streptomyces bygroscopicus. J Gen Microbiol 130, 2549-2558.

Romero, J., Liras, P. \& Martin, J. F. (1984). Dissociation of cephamycin and clavulanic acid biosynthesis in Streptomyces clavuligerus. Appl Microbiol Biotechnol 20, 318-325.

Sarrubi, E., Rudd, K. E. \& Cashel, M. (1988). Basal ppGpp level adjustment shown by new spo'T mutants affects steady state growth rates and $r r n$ A ribosomal promoter regulation in Escherichia coli. Mol Gen Genet 213, 214-222.

Simuth, J., Hudec, J., Chau, H. T., Danyi, O. \& Zelinka, J. (1979). The synthesis of highly phosphorylated nucleotides, RNA and protein by Streptomyces aureofaciens. $J$ Antibiot 32, 53-58.

Strauch, E., Takano, E., Baylis, H. A. \& Bibb, M. J. (1991). The stringent response in Streptomyces coelicolor A3(2). Mol Microbiol 5, 289-298.

Weatherburn, M. W. (1967). Phenol-hypochlorite reaction for determination of ammonia. Anal Chem 39, 971-974.

Received 27 October 1995; revised 23 January 1996; accepted 5 February 1996. 